\section{Endoscopic Third Ventriculostomy in Obstructive Infantile Hydrocephalus: Remarks about the So-Called 'Unsuccessful Cases'}

\author{
Pasquale Gallo $^{a} \quad$ Alexandru Szathmari ${ }^{a} \quad$ Sara De Biasi ${ }^{b} \quad$ Carmine Mottolese $^{a}$ \\ a Pediatric Neurosurgery Unit, Hôpital Neurologique et Neurochirurgical, 'Pierre Wertheimer', Bron, France; \\ ${ }^{b}$ Department of Biomedical Sciences, University of Modena and Reggio Emilia, Modena, Italy
}

(C) S. Karger AG, Basel

PROOF Copy
for personal
use only

ANY DISTRIBUTION OF THIS

ARTICLE WITHOUT WRITTEN

CONSENT FROM S. KARGER

AG, BASEL IS A VIOLATION OF THE COPYRIGHT.

\section{Key Words}

Endoscopic third ventriculostomy $\cdot$ Infancy $\cdot$ Obstructive hydrocephalus $\cdot$ Prognostic factors $\cdot$ Outcome shunt malfunction

\begin{abstract}
Background: The failure rate following endoscopic third ventriculostomy (ETV) in infants younger than 2 years of age has been reported to be higher compared with that of older children, and it is unclear whether ETV might be superior to shunt placement in this age group. Methods: Between 2003 and 2009, 23 patients younger than 6 months and without a previous history of shunting underwent ETV in our institution. A review of the literature was performed on the basis of publications presenting detailed data on age and etiology in every single patient. Results: In our own patients, total success rate was $39.1 \%$. In the successful cases, median age was 140 days, whereas in the unsuccessful cases it was 47 days. The difference between the two groups was statistically significant $(p=0.01)$. The median ages of both successful and unsuccessful groups corresponded to data gained from an analysis of the literature ( $p=0.04)$. At a median follow-up of 47 months, 2 out of 14 patients shunted after a failed ETV were revised for ventriculoperitoneal shunt malfunction. Conclusion: The impact of age on ETV failure in infants is
\end{abstract}

\begin{tabular}{ll}
\hline KARGER & ( 2011 S. Karger AG, Basel \\
Fax +4161306 1234 $34-2291 / 11 / 0000-0000 \$ 38.00 / 0$ \\
$\begin{array}{l}\text { E-Mail karger@karger.ch } \\
\text { www.karger.com }\end{array}$ & $\begin{array}{l}\text { Accessible online at: } \\
\text { www.karger.com/pne }\end{array}$
\end{tabular}

clear and becomes crucial during the first 2 months of life, even when excluding etiological factors. Nevertheless, age cannot be considered the only parameter of the decisionmaking process, especially in these very young patients. Probably, the definition of 'unsuccessful ETV' should be reevaluated in light of decreased risk of shunt malfunction observed after a failed ETV.

Copyright $\odot 2011$ S. Karger AG, Basel

\section{Introduction}

Endoscopic third ventriculostomy (ETV) is a well-established procedure for the treatment of obstructive hydrocephalus although outcome is reported to be worse in small children and especially in infants. Conflicting reports on which patients are most likely to benefit from the procedure are animating the neurosurgical literature. The debate mainly focuses on the influence of age [1-6], etiology [7-15], or both [16-20], and on the success rates of ETV.

Publications in favor of an influence of age on ETV success highlight the highest failure rates in children below a defined age cutoff ranging from 6 months to 2 years; however, the worst outcome and controversies concern the population of premature newborns and infants less

Pasquale Gallo

Pediatric Neurosurgery Unit

Hôpital Neurologique et Neurochirurgical, 'Pierre Wertheimer'

FR-

Tel. $\mathbf{\square} \mathbf{0}$, E-Mail $\mathbf{\square}$ 
Table 1. Summary of patient characteristics and outcomes

\begin{tabular}{|c|c|c|c|c|c|c|c|c|c|}
\hline Patient/sex & $\begin{array}{l}\text { Age } \\
\text { days }\end{array}$ & Diagnosis & $\begin{array}{l}\text { Preoperative signs/ } \\
\text { symptoms }\end{array}$ & Procedure & Re-ETV & Complications & Outcome $e^{1}$ & $\begin{array}{l}\text { Follow-up } \\
\text { months }\end{array}$ & $\begin{array}{l}\text { VPS revisions } \\
\mathrm{n}\end{array}$ \\
\hline $1 \mathrm{AA} / \mathrm{F}$ & 142 & IAS & tense $\mathrm{AF}$ and $\mathrm{IHC}$ & ETV & - & - & VPS (8) & 49 & - \\
\hline $2 \mathrm{BK} / \mathrm{F}$ & 55 & PFC & vomiting and setting- & ETV & - & - & VPS (20) & 12 & - \\
\hline $3 \mathrm{BM} / \mathrm{F}$ & 139 & IAS & tense $\mathrm{AF}$ and $\mathrm{IHC}$ & ETV & after 26 days & - & VPS (40) & 64 & - \\
\hline $4 \mathrm{BA} / \mathrm{M}$ & 65 & DWM & tense $\mathrm{AF}$ and IHC & $\mathrm{ETV}+\mathrm{ECC}$ & - & - & VPS (42) & 19 & - \\
\hline $5 \mathrm{BL} / \mathrm{F}$ & 1 & PHH & antenatal diagnosis & ETV & - & - & VPS (13) & 84 & 1 (after 17 months) \\
\hline $6 \mathrm{CT} / \mathrm{F}$ & 36 & DWM & tense $\mathrm{AF}, \mathrm{IHC}$ and & $\mathrm{ETV}+\mathrm{ECC}$ & - & - & VPS (22) & 19 & - \\
\hline $7 \mathrm{CJ} / \mathrm{M}$ & 83 & $\mathrm{AH}$ & antenatal diagnosis & ETV & - & - & VPS (29) & 67 & - \\
\hline $8 \mathrm{DJ} / \mathrm{F}$ & 6 & IAS & antenatal diagnosis & ETV & - & - & VPS (132) & 45 & - \\
\hline $9 \mathrm{DA} / \mathrm{F}$ & 31 & $\mathrm{PHH}$ & antenatal diagnosis & ETV & - & - & VPS (11) & 75 & $\begin{array}{l}2 \text { (after } 11 \text { and } 41 \\
\text { months) }\end{array}$ \\
\hline $10 \mathrm{DS} / \mathrm{M}$ & 150 & $\mathrm{OEH}$ & setting-sun sign & ETV & - & - & shunt-free & 6 & - \\
\hline $11 \mathrm{FA} / \mathrm{M}$ & 170 & $\mathrm{CM}$ & tense $\mathrm{AF}$ and IHC & ETV & - & - & shunt-free & 81 & - \\
\hline $12 \mathrm{FF} / \mathrm{F}$ & 18 & QC & antenatal diagnosis & $\mathrm{ETV}+\mathrm{ECC}$ & - & seizures & VPS (105) & 6 & - \\
\hline $13 \mathrm{FA} / \mathrm{F}$ & 15 & IAS & antenatal diagnosis & ETV & - & - & shunt-free & 50 & - \\
\hline $14 \mathrm{FC} / \mathrm{F}$ & 169 & IAS & tense $\mathrm{AF}$ and $\mathrm{IHC}$ & ETV & - & - & shunt-free & 58 & - \\
\hline $15 \mathrm{GM} / \mathrm{M}$ & 140 & IAS & tense AF and IHC & ETV & - & - & shunt-free & 49 & - \\
\hline $16 \mathrm{KT} / \mathrm{M}$ & 95 & PFC & IHC & ETV & - & - & shunt-free & 73 & - \\
\hline 17 LE/M & 157 & IAS & tense $\mathrm{AF}$ and $\mathrm{IHC}$ & ETV & - & - & shunt-free & 72 & - \\
\hline $18 \mathrm{MS} / \mathrm{M}$ & 80 & $\mathrm{PHH}$ & tense $\mathrm{AF}$ and $\mathrm{IHC}$ & ETV & - & - & VPS (66) & 84 & - \\
\hline $19 \mathrm{MG} / \mathrm{M}$ & 39 & IAS & IHC & ETV & - & - & VPS (15) & 12 & - \\
\hline $20 \mathrm{ML} / \mathrm{F}$ & 138 & IAS & IHC and large head & ETV & - & - & shunt-free & 84 & - \\
\hline $21 \mathrm{RL} / \mathrm{M}$ & 34 & $\mathrm{PHH}$ & antenatal diagnosis & ETV & - & - & VPS (14) & 84 & - \\
\hline $22 \mathrm{SD} / \mathrm{F}$ & 70 & $\mathrm{PFC}$ & $\begin{array}{l}\text { tense } \mathrm{AF}, \mathrm{IHC} \\
\text { vomiting }\end{array}$ & ETV & - & - & $\operatorname{VPS}(7)$ & 26 & - \\
\hline $23 \mathrm{WL} / \mathrm{M}$ & 45 & IAS & $\mathrm{IHC}$ & ETV & - & forniceal injury & shunt-free & 15 & - \\
\hline
\end{tabular}

${ }^{1}$ The interval between ETV and shunt insertion is given in parentheses (days).

$\mathrm{PFC}=$ Posterior fossa cyst; DWM = Dandy-Walker malformation; OEH = occipital encephalocele-associated hydrocephalus; CM = Chiari I malformation; $\mathrm{QC}=$ quadrigeminal cyst; $\mathrm{AF}=$ anterior fontanel; $\mathrm{IHC}=$ increased head circumference; ECC $=$ endoscopic cystocisternostomy.

than 6 months of age with several studies showing success rate of ETV ranging from 0 to $67 \%[2,10,12,15,18$, 21-26].

We retrospectively analyzed the data of 23 infants younger than 6 months with obstructive hydrocephalus admitted to our Pediatric Neurosurgical Unit in Bron (Lyon) who underwent ETV, as a first choice of treatment, with the intent to assess its effectiveness and discuss the reasons of its failure. We also performed a review of the literature looking for a possible dependence of ETV failure on age or etiology of hydrocephalus.

\section{Material and Methods}

Between January 2003 and September 2009, 183 pediatric ETVs (population younger than 18 years) were performed, including 23 infants less than 6 months of age with diagnosed obstructive hydrocephalus and without a previous history of shunting. In the 23 patients considered in our study, age ranged from 1 to 170 days with a median age of 70 days, and male:female ratio was
11:12. Diagnosis of hydrocephalus was made on the basis of clinical manifestation and on the basis of magnetic resonance imaging (MRI) in the majority of cases or indirectly inferred from triventricular dilatation in CT scan or ultrasound examination. Idiopathic aqueductal stenosis (IAS) was the etiology of hydrocephalus in 10 infants. The other etiologies were posthemorrhagic hydrocephalus $(\mathrm{PHH})$ in 4 patients, posterior fossa cysts in 3 patients, Dandy-Walker malformation in 2 patients, Chiari I malformation in 1 patient, quadrigeminal cyst in 1 patient, hydrocephalus associated with occipital encephalocele in 1 patient and triventricular hydrocephalus in 1 patient with achondroplasia. No children had a shunt device before ETV. Patients with DandyWalker malformation and the patient with quadrigeminal cyst also underwent endoscopic cystocisternostomy during the same surgery. The patient with occipital encephalocele developed hydrocephalus 4 months after the excision of the encephalocele sac with repair of the defect had been conducted. A summary of patient characteristics and outcome is listed in table 1.

ETV procedures were performed with a rigid endoscope (Hopkins $30^{\circ}, \mathrm{Karl}$ Storz, Tuttlingen, Germany) at the lateral edge of the open anterior fontanel or a right frontal burr hole placed slightly anterior to the coronal suture and medial to the midpupillary line. The same procedure was followed in all cases: the third ventricular floor was fenestrated between the mamillary bodies 


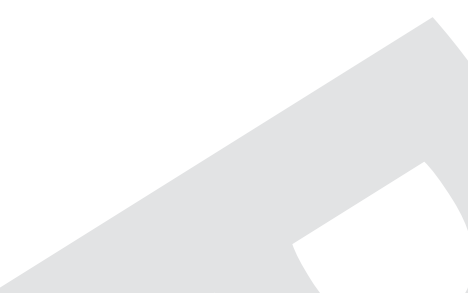

Fig. 1. Bar graph showing age distribution in both outcome groups (our own series). a For all patients. b For patients with IAS.
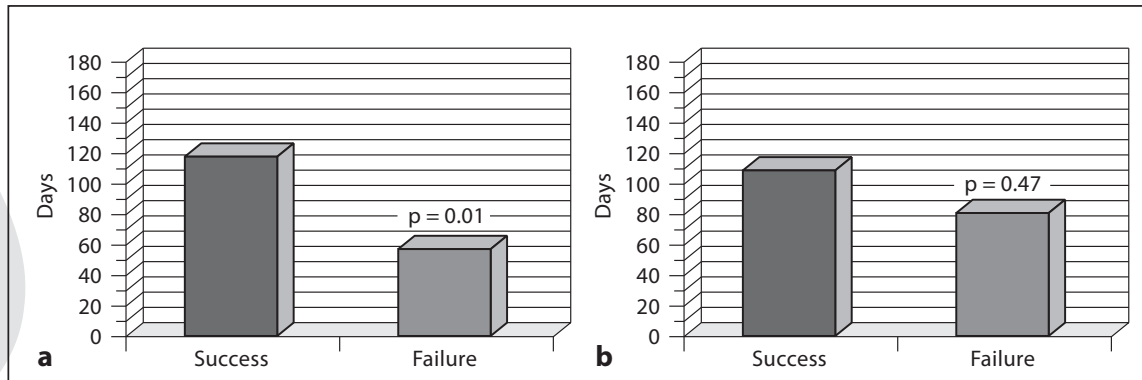

toneal shunt insertion because of recurrence of clinical and radiological signs of hydrocephalus 2 weeks later. In the 9 successful cases, etiology was IAS in 6 patients, Chiari I malformation in 1 patient, posterior fossa cyst in 1 patient and occipital encephalocele in 1 patient; the median age of this group was 140 days and the mean age 119 days (range 15-170). In the ETV failure group the median age was 47 days and the mean age 57 days (range 1-142). The differences between the two groups were statistically significant $(\mathrm{p}=0.01)$ and the age distribution showed a strong tendency for failure to occur more frequently in the first 2 months of life. When analyzing infants only with IAS (only 10 patients), similar distributions, but not significant ( $\mathrm{p}=0.47$ ), were found (fig. 1).

In patients younger than 2 months $(\mathrm{n}=10)$, success rate was $20 \%$ while in patients from 2 to 6 months of age ( $n=13$ ), success rate was $53.8 \%$. The highest success rate was obtained in the primary aqueductal stenosis group with a successful ETV in 6 out of 10 patients. In infants with IAS younger than 2 months $(n=4)$ the success rate was $50 \%$, whereas in patients from 2 to 6 months $(n=6)$ it was $66.6 \%$. In patients with etiology other than IAS ( $n=13$ ) success rate of ETV was $23 \%$ and all successful procedures were performed in infants older than 2 months of age.

At a median follow-up of 47 months, 2 out of 14 infants (14.2\%) shunted after a failed ETV have been surgically revised for VPS malfunction. Both were 1 month old and underwent ETV for PHH. The first had one episode of VPS malfunction after 17 months from the implant, whereas the other had two episodes after 11 and 41 months, respectively.

\section{Analysis of Literature Data}

Careful analysis of the literature, looking for a possible dependency of ETV failure on age or etiology of hydrocephalus, was performed on the basis of publications presenting sufficiently detailed data of every single patient 


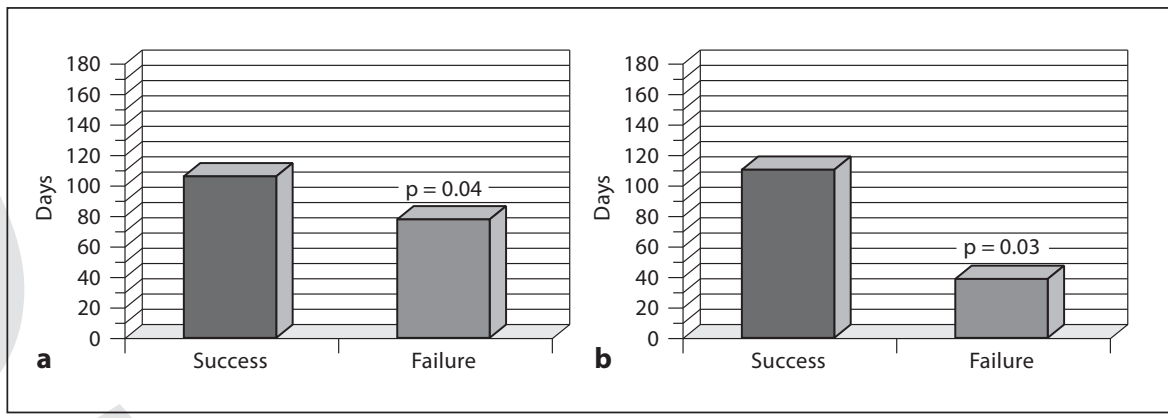

Fig. 2. Bar graph showing age distribution in both outcome groups (data from the literature). a For all patients. b For patients with IAS.

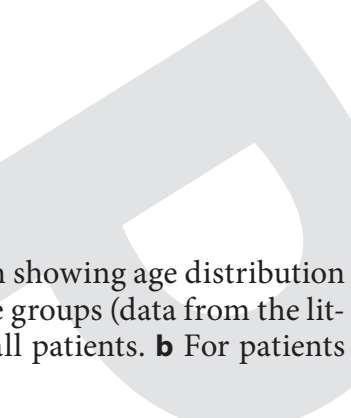

(e.g. in the form of tables presenting raw data) to allow an exact analysis of both patient age and etiology of the hydrocephalus. Only infants younger than 6 months of age, who underwent ETV as a first choice of treatment and with follow-up times of at least 6 months, if not shunted, were included in the meta-analysis.

The publications selected for meta-analysis $[2,4,21$, $22,24,27-30]$ give detailed data on ETV outcome in 53 infants (median age 86 days).

Overall, ETV was successful in 21 patients (39.6\%) and eventually failed in 32 patients. In infants with a successful ETV median age was 120 days and mean age 107 days (range 0-183), whereas in nonsuccessful cases median age was 60 days and mean age 78 days (range $8-188$ ). The differences were statistically significant $(\mathrm{p}=0.04)$. In patients younger than 2 months of age $(n=22)$, success rate was $22.7 \%$ while in patients from 2 to 6 months of age $(\mathrm{n}=31)$, success rate was $51.6 \%$.

In the IAS group $(n=20)$, ETV was successful in $50 \%$ of cases. Median and mean ages were 135 and 112 days, respectively, in successful cases and 33 and 40 days in unsuccessful cases. The differences were statistically significant $(\mathrm{p}=0.03)$ with a success rate in infants less and older than 2 months of age of 25 and $87.5 \%$, respectively (fig. 2). The success rate of ETV in patients with etiology other than IAS $(\mathrm{n}=33)$ was $33 \%$.

\section{Discussion}

The analysis of the literature, confirming our data, shows that overall success rate of ETV, as a first choice of treatment, for children younger than 6 months is about $40 \%$. This finding is also supported by the recent publication by Kulkarni et al. [3] that assessed ETV outcome in a large cohort of children (618 patients younger than 19 years) collected from a collaborative international network and developed a simplified scoring system to pre-

4

Pediatr Neurosurg 324913 dict a successful ETV. This is one of the largest sample sizes currently in the literature validated with a rigorous statistical technique. In their study, age was the strongest predictor of success with infants, especially those younger than 6 months (99 patients), having the lowest predicted ETV success (44.4\%) with progressively higher success seen as a child ages; the effect of etiology and presence of a previous CSF shunt appeared to be significant but much less in magnitude than age.

Warf et al. [31] reported an impressive single-center prospective series of children treated with ETV; the success rate of the procedure in infants younger than 6 months was $34 \%$. However, two remarkable peculiarities of this study must be pointed out: the dominant etiologies of postinfectious and myelomeningocele-associated hydrocephalus and the unilateral/bilateral choroid plexus cauterization performed during the endoscopic procedure.

The finding of a probability of ETV success gradually increasing over time during the first year of life is confirmed also by a retrospective German multicenter study [32] and by the large series reported from Jones et al. [33].

When we analyzed the age distribution of ETV outcome in our population study and in the analysis of the literature, we found a tendency for failures to occur more frequently in the first 2 months. The existence of a cutoff age for the success rate of ETV during the first 6 months was reported by other studies [22, 25, 34], also in the series of Ogiwara et al. [26] only based on infants younger than 6 months.

We are convinced that something happens over the course of time that changes the pathophysiology of CSF flow and increases the success rate of ETV over time. Another factor influencing the lower reported success rate in younger infants is, probably, the definition of 'unsuccessful ETV'. Considering a longer time of adaptation, in comparison with adults, as the reason of persistence of higher ICP despite a good stoma [35], we think that some 
patients (even in our group) are evaluated as unsuccessful and shunted too early.

Regarding the etiology of hydrocephalus, our study, supported by the analysis of the literature, confirms the highest previously reported ETV success rate worldwide in infants with triventricular hydrocephalus caused by isolated primary aqueductal stenosis and a very low success rate in patients with $\mathrm{PHH}$.

Patients with $\mathrm{PHH}$, in our series, were all younger than 3 months of age and ETV eventually failed in all cases. The median interval between ETV and shunt insertion was 13.5 days. Our failure in $\mathrm{PHH}$ is in line with many reports in the literature and reflects our inability, to date, to determine the contribution of hyporesorption in patients with $\mathrm{PHH}$ or postinfectious hydrocephalus.

In case of $\mathrm{PHH}$, a promising approach is to determine the proportion of hyporesorption by examining the transforming growth factor- $\beta_{1}$ level in CSF, as recently reported by Lipina et al. [36]. In our opinion, their study opens up a new scenario for decision making in $\mathrm{PHH}$ and goes in the right direction: improving patient selection by use of biological markers waiting for a progress in imaging tools. Nevertheless, to date, taking an accurate medical history from the parents (any suggestion of postnatal or prenatal bleeding, fetal infection or postnatal meningitis must not be overlooked) remains the first step towards identifying possible risk factors for an underlying problem associated with, or leading to, impaired absorption of CSF [37].

An interesting finding in our series is that patients shunted after a failed ETV showed a decreased risk of shunt malfunction compared with our own previous experience and with the known risk of shunt malfunction in shunted hydrocephalic patients reported in the literature $[38,39]$.

We revised only 2 patients out of 14 (14.2\%) during a median follow-up time of 47 months. This phenomenon, that a failed ETV may have some advantages over time in terms of lower revision rate, was also observed by Beem and Grotenhuis [40].

Shim et al. [41] compared the outcome of 31 infants treated with implantation of VPS and ETV and of 45 infants treated only with VPS. They found a higher success rate in the VPS plus ETV group (success was defined as no need for any subsequent surgical procedure of CSF diversion) with remarkable results in $\mathrm{PHH}$ and postmeningitic hydrocephalus. They did not try to provide evidence for the continuing patency of any of the ETVs or VPSs and suggested that the functioning procedure in the VPS plus ETV group could replace the malfunction-

'Unsuccessful' ETV in Infants ing one [41]. We do not speculate about this phenomenon but we think that it deserves further investigation.

Despite the increasing popularity of ETV, there is no consensus on which is the treatment of choice for infantile hydrocephalus. Controversy continues over which are appropriate candidates for the endoscopic procedure essentially because of our incomplete understanding of hydrocephalus and, above all, of the embryogenesis and the morphological/functional development of CSF dynamics. Despite a variety of classification systems for hydrocephalus have been suggested [17, 42-47], the conventional 'bulk flow' model [48] - even if it fails to explain other forms of hydrocephalus than that caused by obstruction of the intraventricular CSF pathways or ventricular outflow - remains the most attractive for neurosurgeons probably because, beyond the descriptive and simplified aspect of hydrocephalus, it implies alternatives of treatments.

However, in the last years, the concept of communicating versus obstructive hydrocephalus has been challenged; it was suggested that variable sites for obstruction to flow may be important for treatment, and that there could be a number of parallel flow routes that are genetically determined and age-dependent $[49,50]$.

The hydrodynamic hypothesis suggested by Greitz et al. [51] and Greitz [52] considers, in addition to a pure bulk flow problem, the dynamic pulsatile nature of the CSF movement in concert with the venous and arterial pulsatility and the pulsatile movement of the brain itself. The hydrodynamic viewpoint could explain how, apart from the intraventricular interruption of CSF bulk flow, an obstruction of the intraventricular and extraventricular CSF spaces changes local and global compliance and in consequence, pulsatility patterns, which leads to a hydrocephalic condition [51, 52]. Future therapy of pediatric hydrocephalus could be improved when more detailed knowledge of the CSF flow routes and cerebral hydrodynamics is forthcoming.

\section{Conclusion}

Based on our data, on the review of the literature and above-mentioned citations we can doubtless affirm that the pathophysiology of hydrocephalus remains the very Achilles' heel of any treatment paradigms of infantile hydrocephalus.

The major limit of all case series in the literature, even in our study, is the unavoidable subjectivity in defining etiology - secondary versus primary aqueductal steno-

Pediatr Neurosurg 324913 
sis - and 'unsuccessful ETV' which follows the decision to shunt, which is, sometimes, too hasty considering the longer time of adaptation in infants. At the current state of knowledge, looking forward to the results of the ongoing International Infant Hydrocephalus Study trial, the endeavor to improve success rate by selection of patients should not be exaggerated because the risk is to exclude some patients who might benefit from the procedure. In infants with etiology other than primary aqueductal stenosis we probably have to reevaluate the definition of 'unsuccess', considering also the finding that patients shunted after a failed ETV could present a decreased risk of shunt malfunction.

\section{References}

1 Drake JM: Endoscopic third ventriculostomy in paediatric patients: the Canadian experience. Neurosurgery 2007;60:881-886.

2 Koch D, Wagner W: Endoscopic third ventriculostomy in infants of less than 1 year of age: which factors influence the outcome? Childs Nerv Syst 2004;20:405-411.

3 Kulkarni AV, Drake J, Mallucci CL, Sgouros S, Roth J, Constantini S: Endoscopic third ventriculostomy in the treatment of childhood hydrocephalus. J Pediatr 2009;155: 254-259.

4 Kim SK, Wang KC, Cho BK: Surgical outcome of pediatric hydrocephalus treated by endoscopic III ventriculostomy: prognostic factors and interpretation of postoperative neuroimaging. Childs Nerv Syst 2000;16: 161-169.

5 Teo C, Jones R: Management of hydrocephalus by endoscopic third ventriculostomy in patients with myelomeningocele. Pediatr Neurosurg 1996;25:57-63.

6 Teo C: Third ventriculostomy in the treatment of hydrocephalus: experience with more than 120 cases; in Hellwing D, Bauer BL (eds): Minimally Invasive Techniques for Neurosurgery. Berlin, Springer, 1998, pp 7376.

7 Beems T, Grotenhuis JA: Long-term complications and definition of failure of neuroendoscopic procedures. Childs Nerv Syst 2004; 20:868-877.

8 Cinalli G, Sainte-Rose C, Chumas P, et al: Failure of third ventriculostomy in the treatment of aqueductal stenosis in children. J Neurosurg 1999;90:448-454

9 Elbabaa SK, Steinmetz M, Ross J, Moon D, Luciano MG: Endoscopic third ventriculostomy for obstructive hydrocephalus in the pediatric population: evaluation of outcome. Eur J Pediatr Surg 2001;11(suppl 1):S52-S54.

10 Faggin R, Bernardo A, Stieg P, Perilongo G, d'Avella D: Hydrocephalus in infants less than six months of age: effectiveness of endoscopic third ventriculostomy. Eur J Pediatr Surg 2009;19:216-219.

11 Gangemi M, Donati P, Maiuri F, Longatti P, Godano U, Mascari C: Endoscopic third ventriculostomy for hydrocephalus. Minim Invasive Neurosurg 1999;42:128-132.
12 Gorayeb PR, Cavalheiro S, Zymberg ST: Endoscopic third ventriculostomy in children younger than 1 year of age. J Neurosurg Pediatrics 2004;100:427-429.

13 Javadpour M, Mallucci C, Brodbelt A, Golash A, May P: The impact of third ventriculostomy on the management of newly diagnosed hydrocephalus in infants. Pediatr Neurosurg 2001;35:188-194.

14 Jones RF, Kwok BC, Stening WA, Vonau M: Third ventriculostomy for hydrocephalus associated with spinal dysraphism: indications and contraindications. Eur J Pediatr Surg 1996;6(suppl 1):5-6.

15 Lipina R, Reguli S, Dolezilovà V, Kuncikovà $M$, Podesvovà $H$ : Endoscopic third ventriculostomy for obstructive hydrocephalus in children younger than 6 months of age: is it a first-choice method. Childs Nerv Syst 2008;24:1021-1027.

16 Abdullah J, Ariff AR, Ghazaime G, Naing NN: Stereotactic neuroendoscopic management of hydrocephalus: a three-year follow up and analysis of Malaysian children with aqueduct stenosis. Stereotact Funct Neurosurg 2001;76:175-180.

17 Boaz JC, Edwards-Brown MK: Hydrocephalus in children: neurosurgical and neuroimaging concerns. Neuroimaging Clin N Am 1999;9:73-91.

18 Buxton N, Macarthur D, Mallucci C, Punt J, Vloeberghs M: Neuroendoscopic third ventriculostomy in patients less than 1 year old. Pediatr Neurosurg 1998;29:73-76.

19 Scarrow AM, Levy EI, Pascucci L, Albright AL: Outcome analysis of endoscopic III ventriculostomy. Childs Nerv Syst 2000;16:442445 .

20 Siomin V, Cinalli G, Grotenhuis A, et al: Endoscopic third ventriculostomy in patients with cerebrospinal fluid infection and/or hemorrhage. J Neurosurg 2002;97:519-524.

21 Baldauf J, Oertel J, Gaab MR, Schroeder WS: Endoscopic third ventriculostomy in children younger than 2 years of age. Childs Nerv Syst 2007;23:623-626.

22 Balthasar AJR, Kort H, Cornips EMJ, Beuls EAM, Weber JW, Vles JSH: Analysis of the success and failure of endoscopic third ventriculostomy in infants less than 1 year of age. Childs Nerv Syst 2007;23:151-155.
23 Buxton N, Macarthur D, Mallucci C, Punt J, Vloeberghs M: Neuroendoscopy in the premature population. Childs Nerv Syst 1998; 14:649-652.

24 Fritsch MJ, Kienke S, Ankermann T, Padoin M, Mehdorn HM: Endoscopic third ventriculostomy in infants. J Neurosurg Pediatrics 2005;103:50-53.

25 Koch-Wiewrodt D, Wagner W: Success and failure of endoscopic third ventriculostomy in young infants: are there different age distributions? Childs Nerv Syst 2006;22:15371541.

26 Ogiwara H, Dipatri AJ Jr, Alden TD, Bowman RM, Tomita T: Endoscopic third ventriculostomy for obstructive hydrocephalus in children younger than 6 months of age. Childs Nerv Syst 2010;26:343-347.

27 Goumnerova LC, Frim DM: Treatment of hydrocephalus with third ventriculostomy: outcome and CSF flow patterns. Pediatr Neurosurg 1997;27:149-152.

28 Jones RFC, Stening WA, Brydon M: Endoscopic third ventriculostomy. Neurosurgery 1990;26:86-92.

29 Murshid WR: Endoscopic third ventriculostomy: towards more indications for the treatment of non-communicating hydrocephalus. Minim Invasive Neurosurg 2000;43:7582.

30 Oertel JMK, Mondorf Y, Schroeder HWS, Gaab MR: Endoscopic diagnosis and treatment of far distal obstructive hydrocephalus. Acta Neurochir 2010;152:229-240.

31 Warf BC, Mugamba J, Kulkarni AV: Endoscopic third ventriculostomy in the treatment of childhood hydrocephalus in Uganda: report of a scoring system that predicts success. JNeurosurg Pediatr 2010;5:143-148.

32 Fritsch MJ, Kehler U, Joedicke A, Boschert J, Wagner W: Endoscopic third ventriculostomy (ETV) in infants under one year of age: a German multicenter study (abstract). Childs Nerv Syst 2005;21:495-496.

33 Jones R, Kadrian D, van Gelder J, et al: Endoscopic third ventriculostomy - our experience in Sidney (abstract). Childs Nerv Syst 2005;21:507.

34 Sacko O, Boetto S, Lauwers-Cances V, Dupuy M, Roux FE: Endoscopic third ventriculostomy: outcome analysis in 368 procedures. J Neurosurg Pediatr 2010;5:68-74. 
35 Di Rocco C, Cinalli G, Massimi L, Spennato P, Cianciulli E, Tamburrini G: Endoscopic third ventriculostomy in the treatment of hydrocephalus in pediatric patients. Adv Tech Stand Neurosurg 2006;31:119-219.

36 Lipina R, Reguli S, Novackovà, L, Podesvovà $\mathrm{H}$, Brichtovà E: Relation between TGF- $\beta 1$ levels in cerebrospinal fluid and ETV outcome in premature newborns with posthemorrhagic hydrocephalus. Childs Nerv Syst 2010;26:333-341.

37 Beni-Adani L, Biani N, Ben-Sirah L, Constantini S: The occurrence of obstructive vs. absorptive hydrocephalus in newborns and infants: relevance to treatment choices. Childs Nerv Syst 2006;22:1543-1563.

38 Di Rocco C, Marchese E, Velardi F: A survey of the first complication of newly implanted CSF shunt devices for the treatment of nontumoral hydrocephalus. Cooperative survey of 1991-1992 Education Committee of the ISPN. Childs Nerv Syst 1994;10:321-327.

39 Sainte-Rose C, Hoffman HJ, Hirsch JF: Shunt failure; in Marlin AE (ed): Concepts in Pediatric Neurosurgery. Basel, Karger, 1989, pp 7-20.
40 Beems T, Grotenhuis A: Is the success rate of endoscopic third ventriculostomy age dependent? An analysis of the results of endoscopic third ventriculostomy in young children. Childs Nerv Syst 2002;18:605-618.

41 Shim KW, Kim DS, Choi JU: Simultaneous endoscopic third ventriculostomy and ventriculoperitoneal shunt for infantile hydrocephalus. Childs Nerv Syst 2008;24:443-451.

42 Bajpai M, Kataria R, Bhatnagar V, et al: Management of hydrocephalus. Indian J Pediatr 1997;64:48-56.

43 Brockmeyer D, Abtin K, Carey L, Walker ML: Endoscopic third ventriculostomy: an outcome analysis. Pediatr Neurosurg 1998; 28:235-240.

44 Cinalli G, Salazar C, Mallucci C, Yada JZ, Zerah M, Sainte Rose C: The role of endoscopic third ventriculostomy in the management of shunt malfunction. Neurosurgery 1998;43:1323-1327, discussion 1327-1329.

45 Cinalli G: Alternatives to shunting. Childs Nerv Syst 1999;15:718-731.

46 Oi S: Development in harmony. Childs Nerv Syst 2004;20:693-701.

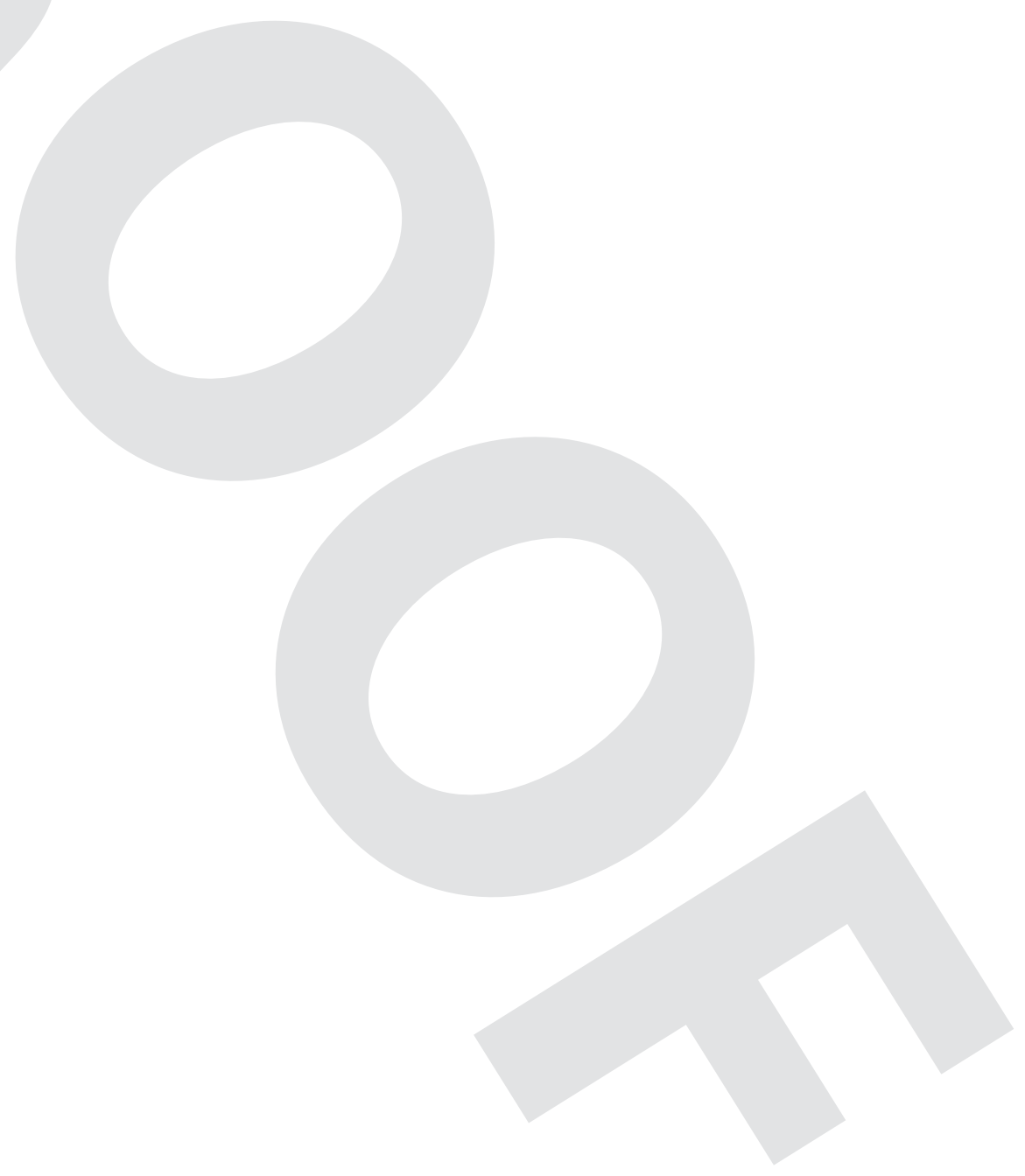

47 Oi S, Abbott R: Loculated ventricles and isolated compartments in hydrocephalus: their pathophysiology and the efficacy of neuroendoscopic surgery. Neurosurg Clin N Am 2004;15:77-87.

48 Dandy WE, Blackfan KD: Internal hydrocephalus: an experimental, clinical and pathological study. Am J Dis Child 1914;8: 406-481.

49 Oi S, Di Rocco C: Proposal of 'evolution theory in cerebrospinal fluid dynamics' and minor pathway hydrocephalus in developing immature brain. Childs Nerv Syst 2006;22: 662-669.

50 Zhang J, Williams MA, Rigamonti D: Genetics of human hydrocephalus. J Neurol 2006; 10:1255-1266.

51 Greitz D, Greitz T, Hindmarsh T: A new view on the CSF-circulation with the potential for pharmacological treatment of childhood hydrocephalus. Acta Paediatr 1997;86:125132.

52 Greitz D: Radiological assessment of hydrocephalus: new theories and implications for therapy. Neurosurg Rev 2004;27:145-165. 